\title{
Hubungan Sabat dan Keselamatan Dalam Perjanjian Lama
}

\author{
Samuel Gerald Pelealu \\ Sekolah Tinggi Teologi Bina Muda Wirawan Medan \\ Sance Mariana Tameon \\ Institut Agama Kristen Negeri Kupang \\ sancemariana82@gmail.com \\ Tri Octavia Oematan \\ Institut Agama Kristen Negeri Kupang
}

\begin{abstract}
The Sabbath is God's mandate for man to rest from all affairs and work. It began when God stopped creating the heavens and the earth and everything in them on the seventh day (Genesis 2:1-3). God appointed the Sabbath as a day of rest. Since God rested, humans who were created in God's image must rest also. One of the most beautiful blessings that come from the Sabbath is refreshment. The Sabbath was closely related to God's action in saving humankind from destruction. This study aimed to analyze the relationship between the Sabbath and salvation in the Old Testament. The literature review is used as the method where the author looks for the main source of research and then analyzes it to find the meaning of the data. The results show that the Sabbath becomes a sign of the covenant and symbol of the special relationship in grace between God-the Redeemer, and His chosen people. The Sabbath had become a sign that reminded the Israelites and believers that God by His grace had sanctified, chosen, and delivered them. The Sabbath was a picture of salvation by God's sovereign grace in exodus. The Sabbath interpreted as people's gratitude expression for the goodness of God who has saved, redeemed and freed humankind from slavery and slavery of the sin.
\end{abstract}

Keywords: sabbath; salvation; holy; rest; covenant

\begin{abstract}
Abstrak
Sabat merupakan mandat Allah bagi manusia untuk beristirahat dari segala urusan dan pekerjaan. Hal ini dimulai ketika Allah berhenti menciptakan langit dan bumi serta segala isinya pada hari ketujuh (Kejadian 2:1-3). Hari Sabat ditentukan Allah sebagai hari peristirahatan. Karena Allah beristirahat, maka manusia yang diciptakan menurut gambar Allah juga harus beristirahat. Salah satu berkat terindah yang diperoleh dari hari Sabat adalah penyegaran kembali. Sabat juga erat kaitannya dengan tindakan Allah dalam menyelamatkan manusia dari kebinasaan. Penelitian ini bertujuan untuk mengkaji mengenai hubungan Sabat dan keselamatan dalam Perjanjian Lama. Metode yang dipakai adalah content analysis/analisis isi dimana penulis mencari sumber utama penelitian lalu menganalisis untuk menemukan makna yang terkandung dalam data tersebut. Hasil penelitian menunjukkan bahwa Sabat menjadi tanda kovenan, dan merupakan simbol dari hubungan khusus dalam anugerah antara Allah-Penebus dan orang-orang pilihan-Nya. Sabat telah menjadi tanda yang mengingatkan bangsa Israel dan orang percaya bahwa Allah dengan rahmatNya telah menguduskan, memilih, dan melepaskan mereka. Sabat menjadi gambaran dari keselamatan oleh anugerah Allah yang berdaulat dalam peristiwa eksodus. Sabat harus dimaknai sebagai ungkapan syukur umat atas kebaikan Allah yang telah menyelamatkan, menebus dan membebaskan manusia dari perbudakan dan perhambaan dosa.
\end{abstract}

Kata kunci: sabat; keselamatan; kudus; peristirahatan; perjanjian 


\section{Pendahuluan}

Kata sabat muncul pertama kali dalam Perjanjian Lama di kitab Keluaran 20:11. Sebenarnya sejak penciptaan gambaran mengenai sabat sudah ada yaitu dalam kitab Kejadian 2:2-3, ketika Allah menyelesaikan seluruh karya penciptaan dan beristirahat pada hari ketujuh dan menguduskannya, namun demikian kata Sabbath tidak digunakan dalam ayat tersebut (Tirtanadi, 2015). Sabat juga selalu dikaitkan dengan hari perhentian Tuhan (Fu, 2010). Dimana Allah berhenti menciptakan langit dan bumi serta segala isinya dan Allah sangat bersukacita melihat karya-Nya, lalu Allah memberkati dan menguduskan atau memisahkan hari itu dari hari-hari yang lain (Ray, 2006). Artinya, sabat ditetapkan oleh Allah bagi Adam dan seluruh keturunannya termasuk umat Tuhan di zaman sekarang.

Sabat merupakan mandat Allah bagi manusia untuk beristirahat dari segala urusan dan pekerjaan. Pada hari itu, manusia harus beribadah, menyembah Dia yang telah menciptakan langit, bumi dan segala isinya, serta yang telah menebus mereka dari perhambaan dosa. Dengan menjalankan hari perhentian manusia juga mendapatkan kelegaan dan kesegaran yang baru. Sejumlah penelitian menunjukkan bahwa kegiatan beribadah bermanfaat bagi kesehatan. Ritual keagamaan seperti berdoa, membaca kebenaran firman Tuhan memberikan suatu kelepasan dari berbagai kepenatan karena adanya komunikasi interpersonal antara manusia dan Tuhan (Hough, 2019). Selain itu, perjumpaan dengan Tuhan pada hari Sabat membuat orang percaya mendapatkan perspektif baru yang seimbang tentang kehidupan dan pelayanan kepada sesama dengan efektif serta makin memaknai keselamatan yang telah dikerjakan Allah dalam diri manusia (Gallagher, 2019).

Allah begitu perhatian dengan bangsa Israel sehingga ketika mereka dibebaskan dari perbudakan di Mesir, Allah memberikan satu hari bagi mereka untuk beristirahat sekaligus sebagai waktu untuk berefleksi atas semua perbuatan ajaib Tuhan dalam kehidupan mereka. Pemberian satu hari bagi bangsa Israel memiliki makna tersendiri yakni dimana hari tersebut belum pernah mereka alami ketika berada di Mesir. Waruwu menjelaskan bahwa sabat secara vertikal bermakna pengakuan terhadap Tuhan Allah yang menciptakan, mengatur, mengelola dan mengontrol segala sesuatu. Sedangkan secara horisontal, Sabat sebagai alarm bagi bangsa Israel atas kebebasan dari perbudakan di tanah Mesir (Waruwu, 2020).

Bertolak dari penelitian ini, peneliti ingin mengkaji lebih dalam mengenai sabat dan keselamatan dalam perjanjian lama sebab ada banyak literatur yang secara teoritis membahas tentang sabat. Studi mengenai pemeliharaan hari sabat (Rosenberg dkk 2016; Superville dkk 2014, Putih dkk 2015)(Speedling, 2019), hubungan sabat dengan ketaatan mental, psikis, dan kesehatan spiritual (Hough 2019), peran sabat dalam kehidupan orang percay (Waruwu, 2020) sabat dalam pandangan orang Yahudi ortodoks (Bix, 2020). Namun belum ada yang membahas secara spesifik mengenai hubungan sabat dengan keselamatan dalam konsep Perjanjian Lama.

\section{Metode}

Penelitian ini menggunakan pendekatan Studi Kepustakaan (Library Research). Studi kepustakaan merupakan suatu studi yang digunakan dalam mengumpulkan informasi dan data dengan bantuan berbagai macam material yang ada di perpustakaan seperti dokumen, buku, majalah, kisah-kisah sejarah (Abdi Mirzaqon; Budi Purwoko, 
2018). Studi kepustakaan juga mempelajari berbagai buku referensi serta hasil penelitian sebelumnya yang sejenis yang berguna untuk mendapatkan landasan teori mengenai masalah yang akan diteliti.

Teknik analisis data menggunakan metode Content Analysis atau analisis isi. Metode ini dipakai untuk mempelajari teks-teks yang sudah ada dan memungkinkan peneliti untuk mengelola dan meringkas sejumlah informasi atau data secara sistematis. Selain itu, analisis isi juga dapat digunakan untuk menggambarkan fenomena dengan melakukan triangulasi dengan metode penelitian lainnya (Nelson \& Woods, 2011). Dalam analisis ini peneliti terlebih dahulu melakukan proses memilih, membandingkan, menggabungkan dan memilah berbagai informasi berkenaan dengan sabat dan hingga ditemukan yang relevan dengan penelitian ini kemudian menganalisisnya untuk menghasilkan penelitian yang valid dengan temuan yang baru (Abdi Mirzaqon; Budi Purwoko, 2018).

\section{Hasil dan Pembahasan}

\section{Sabat Dalam Perjanjian Lama}

Sebagai Hari Perhentian (Kejadian 2:1-3; Kel. 31:15)

Kata Sabat dalam bahasa Ibrani שָׁבָ ("syabbat", dari akar kata syavat, yang berarti berhenti, melepaskan (Douglas, 2001). Dalam Kitab Kejadian 2:2 “Ketika (Abdi Mirzaqon; Budi Purwoko, 2018) Allah pada hari ketujuh telah menyelesaikan pekerjaan yang dibuat-

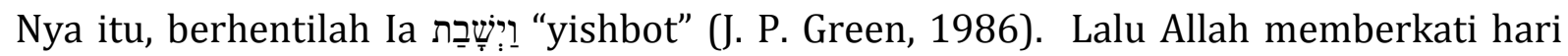
Sabat itu, (Kej. 2:3), dan menguduskannya (Kej. 2:3; Kel. 20:11). Hari ketujuh merupakan hari untuk beristirahat dan atau berhenti bekerja (Gallagher, 2019). Sabat dimaksudkan untuk menjadi waktu tenang bagi manusia dan semua ciptaan untuk berefleksi atas karya Tuhan (Speedling, 2019).

Kata Sabat bukan berarti Allah sama sekali tidak bergerak, melainkan, 1) Allah berhenti dari pekerjaan penciptaan-Nya atau tidak meneruskannya. 2) Allah memelihara dan bersukacita atas semua ciptaan-Nya (Park, 2002). Artinya, Allah adalah Pencipta dan Pekerja yang aktif yang tidak pernah mengenal capek dan tidak membutuhkan waktu untuk beristirahat. Dalam Keluaran 20:11 mencatat "sebab enam hari lamanya TUHAN menjadikan langit dan bumi, laut dan segala isinya, dan Ia berhenti pada hari ketujuh." Ayat ini menunjukkan tentang adanya 'waktu' yang juga merupakan bagian dari ciptaan Allah. Jadi, waktu bukan ada dengan sendirinya, tetapi merupakan hasil dari kuasa dan tujuan penciptaan yang Allah kerjakan. Allah menetapkan siklus waktu, sehingga manusia dapat mendefinisikan adanya hari, bulan dan tahun (Kej. 1:14-18), dan Allah juga yang menentukan adanya satu minggu sebagai tujuh hari (Kej. 2:2-3) Karena waktu adalah bagian dari tatanan yang diciptakan Allah, maka manusia tunduk pada batasanbatasannya, sedangkan Allah berdaulat atasnya (Ray, 2006).

Keluaran 23:12 tertulis, "enam hari lamanya engkau melakukan pekerjaanmu, tetapi pada hari ketujuh haruslah engkau berhenti, supaya lembu dan keledaimu tidak bekerja dan supaya anak budakmu perempuan dan orang asing melepaskan lelah." Kata "perhentian" didefinisikan sebagai penyegaran kembali. Dalam Perjanjian Lama, kata 'penyegaran kembali' berarti 'bernafas'. Jadi, Sabat adalah kesempatan yang diberikan Allah bagi umat ciptaan-Nya untuk bernafas lega kembali ditengah-tengah pekerjaan 
rutin dalam seminggu (Ray, 2006). Dengan beristirahat pada hari Sabat, bangsa Israel diundang untuk memperoleh perhentian bersama Allah (Kej. 2:1-3; Kel. 31:17) (VanGemeren, 2016). Penyegaran kembali bukan hanya bagi manusia, hamba, orang asing melainkan juga bagi binatang. Sabat menjadi waktu bagi manusia berefleksi terhadap hubungannya dengan Tuhan, sesama dan alam ciptaan Tuhan (Speedling, 2019). Fakta inilah yang dimaksudkan Sproul, bahwa Sabat termasuk mandat untuk beristirahat dari segala sesuatu urusan atau pekerjaan, juga merupakan waktu untuk beribadah bersamasama, karena hari itu (Sabat) adalah hari khusus untuk bersukacita atas kebangkitan Kristus dan pengharapan akan Sabat kita di surga (Sproul, 2000).

Dengan demikian, Sabat sebagai hari perhentian menegaskan bahwa ketika manusia mengingat akan janji-janji Tuhan, mereka mendapatkan rasa nyaman dan kelegaan atas pengharapannya. Ketika manusia menghormati hari Tuhan yang mulia, maka mereka akan menikmati sukacita dan kesenangan di dalam Tuhan, sebagaimana janji-Nya dalam Yesaya 58:13-14, “Apabila engkau tidak menginjak-injak hukum Sabat dan tidak melakukan urusanmu pada hari kudus-Ku; apabila engkau menyebutkan hari Sabat "hari kenikmatan", dan hari kudus TUHAN "hari yang mulia"; apabila engkau menghormatinya dengan tidak menjalankan segala urusanmu atau berkata omong kosong, maka engkau akan bersenang-senang karena TUHAN, dan Aku akan membuat engkau melintasi puncak bukit-bukit di bumi dengan kendaraan kemenangan; Aku akan memberi makan engkau dari milik pusaka Yakub, bapa leluhurmu, sebab mulut TUHANlah yang mengatakannya". Ketika manusia memuji-muji Tuhan, maka hatinya penuh dengan sukacita yang mendatangkan kesegaran, kelegaan dan pemulihan dari tekanan dan pergumulan hidup yang menghimpit selama enam hari mereka bekerja. Sabat merupakan waktu perenungan yang dapat mengingatkan manusia dalam relasinya dengan Tuhan, sesama dan alam serta dapat memacu manusia untuk bekerja demi kemuliaan Tuhan (Speedling, 2019).

\section{Sebagai Hari Yang Diberkati dan Dikuduskan (Kej. 2:3; Kel. 20:8; 31:15)}

Kejadian Pasal 2 secara khusus menyebut hari ketujuh Shabat Yom dimana Allah telah berhenti dari segala pekerjaan penciptaan-Nya dan, seperti dengan berkat sebelumnya pada hewan dan manusia, Allah memberkati hari ketujuh ini dan membedakannya dari enam lainnya (Kaseke, 2020). Kekudusan hari Sabat menurut Sproul telah ditetapkan sejak penciptaan. Setelah Allah mencipta selama enam hari, Allah beristirahat pada hari ketujuh dan menguduskannya (Sproul, 2000).

Dengan kalimat perintah "Ingatlah dan kuduskanlah hari Sabat" (Kel.20:8; Ul.5:12), menyatakan bahwa hari itu suci bagi Tuhan dan dipakai-Nya untuk menguduskan orang-orang-Nya (Kel. 31:12-17; Im.19:30; 26:2; Neh.13:15-17; Yeh 20:12,20), dan Tuhan mengundang umatnya untuk mengambil bagian di dalam perhentian-Nya sendiri. Allah membuka waktu agar manusia dapat bersekutu dengan Allah dan sesamanya (Barth \& Barth-Frommel, 2008). Artinya, Allah yang menguduskan Sabat bagi diri-Nya sendiri pada saat penciptaan dan memberikan kesempatan kepada manusia untuk membangun persekutuan dengan Allah dan ciptaan yang lain. 
Menurut Karman, menguduskan hari Sabat merupakan pengakuan bahwa segala hasil bukan semata-mata usaha manusia, melainkan tergantung pada kemurahan Allah, maka pelanggaran hari Sabat ditegur (Yes.58:13), apalagi bila motifnya keserakahan ekonomi (Yer.19:21-27; Am.8:5-6). Dengan meliburkan segala pekerjaan, menunjukkan bahwa kelangsungan hidupnya tergantung pada Tuhan Pemberi Berkat, bukan pada perencanaan yang bagus dan jerih payah manusia. Dengan demikian, kegiatan ekonomi tidak diberhalakan (Karman, 2007).

Hari Sabat sebagai hari yang diberkati Allah adalah untuk mengingatkan umat Allah/bangsa Israel, bahwa Allah sudah mengaruniakan manna yang berlebih sebelum Sabat tiba agar mereka dapat berhenti. Melalui hal ini, Allah memperingatkan manusia/bangsa Israel bahwa pekerjaan dan hasilnya bukan tujuan hidup, melainkan manusia diciptakan untuk berhubungan dengan Allah dan sesamanya. Melanggar kekudusan Sabat dengan tidak berhenti sepenuhnya berarti memisahkan diri dari Allah, dan menajiskan milik-Nya (Barth \& Barth-Frommel, 2008).

Keyakinan tradisioanal Yahudi menekankan hakikat Sabat sebagai waktu yang disucikan Tuhan (Bix, 2020). Hari Sabat dikhususkan/dikuduskan Tuhan agar manusia dapat bersekutu, menyembah, memuliakan Tuhan, mendapatkan ketenangan dan kedamaian di dalam dan melalui Dia (Mat.11:28). Selain memberi kelegaan bagi jiwa, melalui Sabat, manusia juga dapat memberikan istirahat dan kelegaan bagi fisiknya. Bekerja selama enam hari mendatangkan kelelahan fisik dan psikis. Allah menyediakan waktu bagi fisik dan psikis manusia untuk beristirahat agar mendapatkan kesegaran baru dalam menghadapi hari kerja berikutnya. Pada hari Sabat manusia marawat benih keabadian yang ditanam di dalam jiwanya (Bix, 2020). Artinya, Sabat ditetapkan untuk memberikan istirahat dan kelegaan bagi umat. Manusia menguduskan hari Sabat bukan berarti manusia menjadikan hari itu sebagai hari yang keramat, tetapi agar manusia menyembah dan bersekutu dengan Allah pencipta Sabat itu sehingga manusia memiliki kedamaian, ketenangan, sukacita dan kelegaan. Menurut Carter Sabat adalah saat yang tepat bagi manusia untuk menghabiskan waktu bersama dengan Tuhan yang membutuhkan niat dan persiapan (Carter, 2020).

\section{Karya Keselamatan Dalam Perjanjian Lama}

Dalam Perjanjian Lama, walaupun keselamatan umat manusia sudah ditetapkan Allah sejak kekekalan, namun rencana keselamatan Allah bagi manusia dinyatakan Alkitab setelah kejatuhan manusia dalam dosa. Rahmat Tuhan ini dinyatakan melalui firman-Nya dalam Kej. 3:15, yaitu melalui keturunan manusia /perempuan (Yesus Kristus) yang akan meremukkan kepala keturunan ular (iblis). Sementara menantikan Inkarnasi Kristus, Allah menetapkan persembahan korban melalui penumpahan darah binatang sebagai pengganti nyawa manusia (Kej. 3:21; 8:20-21; 22:13) (D. Green, 1984). Jadi, melalui penumpahan darah binatang yang dilakukan terus menerus oleh bangsa Israel sebagai persembahan kepada Allah, menjadi cara untuk meluputkan mereka dari penghukuman Allah. Penggantian ini telah digenapi dan disempurnakan melalui pencurahan darah Kristus di atas kayu salib. 
Dalam kitab Keluaran ada dua peristiwa yang menjadi lambang karya keselamatan Allah bagi umat-Nya Israel, yaitu: 1) Darah anak domba Paskah yang melindungi orangorang Israel dari hukuman mati yang menimpa orang-orang Mesir (Kel.12:13; band. 1 Kor. 5:7). 2) Penyeberangan Laut Teberau oleh orang-orang Israel, yang berarti menyeberang dari kematian kepada hidup baru (Kel.14:30; band. 1 Kor.10:1-2). Kedua pertistiwa tersebut merupakan hal penting bagaimana Allah berintervensi secara langsung dalam diri bangsa Israel dengan memilih menyelamatkan dan membebaskan mereka dari hukuman mati serta memberikan kehidupan yang baru. Dengan adanya keselamatan tersebut, bangsa Israel berkewajiban menaati segala perintah Tuhan seturut dengan sifat kekudusan Tuhan. Karena ketika bangsa Israel taat, maka Allah akan melimpahkan berkat bagi mereka.

Dalam Perjanjian Lama, tipologi karya keselamatan yang dilakukan Kristus dapat dilihat dari beberapa peristiwa, kelembagaan dan upacara-upacara, seperti: melalui Korban Binatang, melalui Keimaman (keimaman Harun dan Melkisedek merupakan gambaran keimaman Kristus), melalui Hari-Hari Besar Tuhan (Paskah, Hari raya Roti Tak Beragi melambangkan Kristus sebagai Roti Hidup, Hari Raya Pendamaian melambangkan Kristus sebagai pendamai manusia dengan Allah). Kota-Kota Perlindungan (Bil. 35; Ul. 19:1-13; Yos. 20), merupakan gambaran Kristus sebagai perlindungan bagi umat-Nya. Dalam Perjanjian Lama, Allah disebut juga sebagai tempat perlindungan (Maz.46:2; 142:6; Yes. 4:6).

Bangsa Israel secara alamiah/biologi adalah keturunan Abraham, Ishak dan Yakub yang telah bertransformasi menjadi satu bangsa yang berhubungan secara khusus dengan Allah Pencipta. Mereka telah menerima janji-janji dari Allah bahwa Ia akan menjadi Allah mereka, dan mereka akan menjadi umat-Nya. Hubungan ini menurut VanGemeren disebut sebagai hubungan kovenantal. Di dalam hubungan ini, Israel dikenal sebagai segulla, yaitu "milik khusus"; dan am, yaitu "umat-Nya", serta nahala, yaitu "warisan-Nya" (Ul. 9:26,29; 1Raja 8:51;Maz.94:5) (VanGemeren, 2016). Ini menunjukkan bahwa, keselamatan yang Allah nyatakan kepada bangsa Israel dan juga kepada setiap orang yang percaya kepada Kristus bertujuan untuk menjadikan mereka milik atau umat kepunyaanNya dan yang menjadi ahli waris kerajaan Allah.

\section{Hubungan Sabat dan Keselamatan Dalam Perjanjian Lama}

Sabat dalam Perjanjian Lama tidak dapat dipisahkan dengan konsep keselamatan. Dimana hal ini tergambar jelas melalui kondisi bangsa Israel yang identik dengan perbudakan. Orang Israel Selama masa perbudakan selalu berseru kepada Tuhan untuk dibebaskan dan Tuhan memakai Musa untuk membebaskan bangsa Israel dari pebudakan di tanah Mesir. Setelah mengalami pembebasan, bangsa Israel hidup di padang gurun dan menikmati berkat Tuhan yang tak terhingga. Salah satunya adalah sabat dimana bangsa Israel diberi waktu beristirahat dari segala bentuk pekerjaan yang sebelumnya mereka tidak nikmati ketika ada dalam masa perbudakan di Mesir.

Sabat menjadi hal penting dalam kehidupan Bangsa Israel yang telah mengalami pembebasan sebab sabat menjadi hari kemerdekaan bangsa Israel dari bentuk-bentuk 
perbudakan dan dosa. Selain itu, sabat juga menjadi hari untuk bersukacita di dalam Tuhan karena umat Tuhan dengan leluasa dapat beribadah kepada Tuhan dan merayakan kebebasan dari perbudakan di Mesir (Tangkudung, 2013).

Allah mengingatkan Israel bahwa dulu mereka budak, sekarang mereka telah merdeka, maka mereka harus tidak boleh memperbudak diri sendiri (dengan pekerjaan) dan orang-orang yang ada dalam rumahnya, termasuk ternak mereka. Barth menyatakan, Allah menyuruh orang Israel memelihara Sabat dengan mengingat bahwa mereka budak di tanah Mesir dan dibebaskan Tuhan. Itulah sebabnya "jangan melakukan sesuatu pekerjaan, engkau ... hambamu laki-laki, hambamu perempuan, atau lembumu atau keledaimu atau orang asing di tempat kediamanmu, supaya ... mereka berhenti seperti engkau juga, Kel.23:10-12 "supaya anak budak perempuan dan orang asing melepaskan lelah" (Barth \& Barth-Frommel, 2008). Sebagai bangsa yang pernah menjadi budak di Mesir dan sudah dibebaskan; Israel harus menerapkan belas kasihan Sabat terhadap orang-orang yang berada di bawah kekuasaan mereka, karena orang-orang itu adalah budak (Douglas, 2001)

Dalam Perjanjian Lama kata keselamatan dikaitkan dengan tindakan Allah membawa keluar umat-Nya keluar dari Mesir (Kel.3:10; 6:5). Barth mengutip pernyataan Wijngaards yang menyatakan, bahwa kata "membawa keluar" menekankan segi pembebasan dan "membawa naik" memandang kepada Allah yang mengantarkan umatNya ke tanah yang dijanjikan-Nya. Lebih lanjut dikatakan bahwa tindakan Allah ini bukan hanya berkaitan dengan memindahkan bangsa Israel keluar dari Mesir ke negeri yang lain, tetapi berarti memindahkan mereka dari perbudakan ke keadaan kemerdekaan. Kata kerja "mengeluarkan dan mengangkat", sama artinya dengan "meluputkan, menyelamatkan, melepaskan, membebaskan, bahkan menebus" dari tanah Mesir (Barth \& Barth-Frommel, 2008).

Selain itu, dalam Kel.6:6, kalimat "Aku akan mengangkat kamu menjadi umat-Ku dan Aku akan menjadi Allahmu, supaya kamu mengetahui, bahwa Akulah TUHAN, Allahmu, yang membebaskan kamu dari kerja paksa orang Mesir". Kata kerja Ibrani nasal yang berarti, "mencabut, mengangkat keluar"), sering dipakai untuk perbuatan Allah yang membebaskan/melepaskan/menyelamatkan (Kel. 3:8; 5:23; 18:4,8-10). Kata kerja lain yang dipakai adalah goal yang digunakan untuk penebusan anggota keluarga yang menjadi budak. Ada juga kata kerja pada, yang memiliki arti lebih luas bukan untuk menebus seorang budak, tetapi untuk menebus harta milik dari kekuasaan orang lain (Kel.13:13). Kata goel (Kel.6:5;15:13; Yes.43:1; 48:20) dan kata pada (Ul.7:8; 9:26; 13:6; 15:15; 21:8; 24:18; 2 Sam.7:23; Mik.6:4), dipakai untuk penebusan secara sukarela. Allah menebus umat-Nya dengan sukarela, karena kasih-Nya dan bukan karena kewajiban (Barth \& Barth-Frommel, 2008).

Di dalam Ulangan 5:12 \& 15 dikatakan "Tetaplah ingat dan kuduskan hari Sabat, seperti yang diperintahkan kepadamu oleh TUHAN, Allahmu” (ay.12) ...Sebab haruslah kau ingat, bahwa engkau pun dahulu budak di tanah Mesir dan engkau dibawa keluar dari sana oleh TUHAN, Allahmu dengan tangan yang kuat dan lengan yang teracung; Itulah sebabnya TUHAN, Allahmu memerintahkan engkau merayakan hari Sabat" (ay.15). Disini 
terdapat kata yang yang berbeda, jika di Keluaran 20:8 kata pertamanya adalah "ingatlah", maka dalam kitab Ulangan 5:12\&15 dimulai dengan kata "Tetaplah ingat" \& "haruslah kau ingat". Maksud kalimat tambahan itu dalam kaitannya dengan Sabat ada dua, yaitu: 1. Bahwa dalam enam hari, Tuhan sebagai Pencipta, telah menjadikan langit dan bumi. 2 . Bahwa umat Allah telah menjadi budak di tanah Mesir, dan Tuhan sebagai Penyelamat, telah melepaskan mereka dengan tindakan penebusan yang dahsyat. Sabat inilah yang disebut Ray sebagai "Sabat Eksodus" dimana Sabat dirayakan untuk memperingati penciptaan ditambah memperingati penebusan yang dikerjakan oleh kuasa Allah yang dahsyat dalam peristiwa Eksodus (Ray, 2006).

Sabat menjadi tanda kovenan, dan merupakan simbol dari hubungan khusus dalam anugerah antara Allah-Penebus dan orang-orang pilihan-Nya. Sabat telah menjadi tanda yang mengingatkan bangsa Israel bahwa Allah dengan rahmat-Nya telah menguduskan, memilih, dan melepaskan mereka. Sebagai tanda anugerah, Sabat menyatakan bahwa keselamatan tergantung pada kuasa Allah dan bukan pada perbuatan manusia. Dan hal ini menunjukkan kepada semua orang Israel dalam komunitas kovenan, bahwa hukuman karena menolak Allah dan anugerah-Nya selalu berupa kematian (kel.31:14) (Ray, 2006). Jadi, arti Sabat yang sesungguhnya bagi Israel adalah bahwa pelepasan atau pembebasan yang Tuhan berikan adalah simbol keselamatan yang akan Dia berikan, dan sebagaimana manusia berdosa menerima pengampunan dosa, maka melalui pengampunan itu mereka dapat menjalin hubungan secara pribadi dengan Tuhan dan menikmati sukacita, kebaikan serta damai sejahtera-Nya.

Sabat berelasi erat dengan keselamatan dalam konteks Perjanjian Lama, karena melalui Sabat orang Israel diingatkan bahwa mereka pernah hidup menderita sebagai budak di bawah kekejaman mandor-mandor Mesir, dan Allah telah memberikan kelegaan kepada mereka (Kel. 1:11-14; Ul. 5:15). Sabat menjadi gambaran dari keselamatan oleh anugerah Allah yang berdaulat dalam peristiwa eksodus. Sabat harus menjadi peringatan bagi manusia bahwa mereka diselamatkan bukan karena hasil kerja mereka, tetapi karena kuasa Allah (Zakaria 4:6 "Bukan dengan keperkasaan dan bukan dengan kekuatan, melainkan dengan roh-Ku, Firman TUHAN semesta alam"). Melalui sabat, bangsa Israel diingatkan bahwa Tuhan selalu memperhatikan umat-Nya dan memberikan kelepasan kepada yang berseru

Sabat mengajarkan manusia bahwa mereka hanya dapat memperoleh peristirahatan penuh dengan berhenti berusaha berdasarkan jerih payah mereka sendiri dan percaya sepenuhnya pada karya penebusan Allah. Penebusan bukan berasal dari manusia; penebusan adalah karya Allah sepenuhnya. "Keselamatan adalah dari TUHAN" (Yunus 2:9). Dengan demikian, Sabat dalam Perjanjian Lama adalah hari untuk penyegaran secara fisik dan rohani serta perayaan penuh sukacita akan penciptaan dan penebusan yang Allah kerjakan (Ray, 2006).

Tuhan memberikan sabat kepada Israel sebagai peringatan atau tanda antara Allah dengan bangsa Israel sebagai umat yang dikuduskan-Nya. Dikuduskan berarti dipisahkan/dikhususkan bagi Tuhan, dan menjadi milik Tuhan. Dengan menaati Sabat manusia menyadari bahwa mereka membutuhkan Tuhan dan hanya Tuhanlah yang 
sanggup melepaskan manusia dari berbagai kemelut kehidupan dan hanya Tuhan sumber keselamatan manusia (Dhung, 2012). Menurut Calvin sabat adalah sebuah perintah agar manusia berhenti bekerja dan mengijinkan Tuhan bekerja. Adalah sebuah keharusan bagi manusia untuk beristirahat agar Tuhan dapat leluasa bekerja di dalam kehidupan manusia (Dhung, 2012).

\section{Implikasi}

Secara praktis Sabat memiliki implikasi dalam hubungannya dengan keselamatan yang Allah kerjakan dalam kehidupan bangsaa Israel dimana mereka diselamatkan dari perbudakan dari kekuasaan Mesir dan memberikan kelepasan serta kebebasan bagi bangsa Israel untuk hidup sebagai orang merdeka tanpa harus dijajah, ditindas dan mengalami penderitaan yang berkepanjangan. Dalam kaitannya dengan gereja dan kekristenan, sabat berimplikasi kepada karya keselamatan yang telah Allah kerjakan dalam diri manusia, dimana Allah dalam inisiatif-Nya membebasakan dan menyelamatkan manusia dari perbudakan dosa melalui kematian Kristus di kayu salib. Dengan menjalankan Sabat, orang percaya memproklamasikan kehidupan kebebasan yang dianugerahkan Tuhan kepada manusia. Selain itu, dengan menjalankan Sabat kesadaran akan kehadiran Tuhan akan terasa. Manusia mengakui akan keterbatasannya dan belajar bergantung serta percaya pada kemahakuasaan Tuhan yang mampu menyelamatkan manusia.

\section{Rekomendasi untuk Penelitian Lanjutan}

Bagi peneliti yang ingin meneliti lebih lanjut dapat mengkaji hubungan Sabat dengan keselamatan dalam Perjanjian Baru. Apakah Sabat hanya ditekankan dalam Perjanjian Lama atau ada juga dalam Perjanjian Baru.

\section{Kesimpulan}

Hari Sabat harus dipahami sebagai hari Tuhan. Hari yang Tuhan ciptakan dan diperuntukkan bagi umat manusia untuk beristirahat dari segala aktifitas pekerjaannya. Melalui istirahat ini, umat manusia mendapatkan kesegaran baru dan memberikan kelegaan bagi fisiknya dari kelelahan setelah bekerja selama enam hari. Bagi umat Allah, bangsa Israel khususnya, hari Sabat bukan hanya sekedar untuk memberikan waktu istirahat dan kelegaan serta kesegaran bagi fisiknya, tetapi yang terutama adalah melalui Sabat, mereka mengingat bahwa Allah telah mencipta dunia dan segala isinya selama enam hari dan berhenti dalam penciptaan-Nya pada hari ketujuh (Sabat). Israel juga harus mengingat bahwa dengan merayakan dan menguduskan Sabat, mereka mengingat dan mengenang akan karya penyelamatan yang Tuhan telah lakukan ketika mereka menjadi budak di tanah Mesir. Dengan memahami semua itu, Israel diberi kesempatan oleh Allah untuk mensyukuri kebaikan dan kemurahan Tuhan atas diri mereka, melalui tindakan memuji, memuliakan dan mengagungkan Tuhan dalam ibadah, doa dan penyembahan kepada-Nya pada hari yang dikhususkan itu. melalui ibadah, doa dan 
penyembahan kepada Tuhan Pencipta yang dapat dilihat melalui kegiatannya dalam membantu sesama yang membutuhkan pertolongan.

Dalam hubungannya dengan orang percaya pada masa kini, merayakan dan menjalankan sabat memiliki makna yang luas dimana manusia diberi kesempatan oleh Tuhan untuk beristirahat dari segala bentuk pekerjaan. Selain itu, sabat menjadi waktu bagi manusia dalam berelasi dengan Tuhan. Sabat juga mengingatkan orang percaya tentang karya keselamaatan yang diinisiasi oleh Allah untuk menebus manusia dari lumpur dosa, sehingga manusia tidak lagi menjadi budak dosa melainkan menjadi orang yang bebas karena darah Kristus telah tertumpah bagi keselamatan umat manusia.

\section{Rujukan}

Abdi Mirzaqon; Budi Purwoko. (2018). STUDI KEPUSTAKAAN MENGENAI LANDASAN TEORI DAN PRAKTIK KONSELING EXPRESSIVE WRITING. 1-8.

Barth, C., \& Barth-Frommel, M.-C. (2008). Teologi Perjanjian Lama 1. Jakarta: BPK Gunung Mulia.

Bix, A. S. (2020). 'Remember the Sabbath': a history of technological decisions and innovation in Orthodox Jewish communities. History and Technology, 36(2), 205239. https://doi.org/10.1080/07341512.2020.1816339

Carter, E. C. (2020). The converging of the ways? - what Sabbath practice can teach us about jewish-christian and intra-religious relations today. Religions, 11(12), 1-10. https://doi.org/10.3390/rel11120661

Dhung, P. K. H. (2012). Pandangan Calvin Tentang Hari Sabat. Veritas, 13, 189-201.

Douglas, J. D. (2001). Ensiklopedia Alkitab Masa Kini, jilid II. Jakarta: Yayasan Komunikasi Bina Kasih.

Fu, T. (2010). Perhentian Hari Sabat. Veritas, 2(Oktober), 231-241.

Gallagher, L. J. (2019). A Theology of Rest: Sabbath Principles for Ministry. Christian Education Journal, 16(1), 134-149.

https://doi.org/10.1177/0739891318821124

Green, D. (1984). Pembimbing Pada Pengenalan Perjanjian Lama. Malang: Gandum Mas.

Green, J. P. (1986). The Interlinear Bible, Hebrew-Greek-English. (Massachusetts:

Hendrickson Publishers.

Hough, H. (2019). Relationships between Sabbath Observance and Mental, Physical, and Spiritual Health in Clergy. Pastoral Psychology, 68(2), 171-193.

https://doi.org/10.1007/s11089-018-0838-9

Karman, Y. (2007). Bunga Rampai Teologi Perjanjian Lama. Jakarta: BPK Gunung Mulia.

Kaseke, F. Y. M. (2020). Perspektif Eco-teologi Kristen Sabat dan Pandemic Covid 19. 5368, 23-31.

Nelson, C., \& Woods, R. H. (2011). The Routledge Handbook of Research Methods in the Study of Religion (M. Stausberg \& S. Engler, ed.). Routledge Taylor and Francis Group.

Park, Y. S. (2002). Tafsiran Kitab Kejadian. Batu: YPPII.

Ray, B. A. (2006). Merayakan Sabat. Surabaya: Momentum. 
Speedling, B. B. (2019). Celebrating Sabbath as a Holistic Health Practice: The Transformative Power of a Sanctuary in Time. Journal of Religion and Health, 58(4), 1382-1400. https://doi.org/10.1007/s10943-019-00799-6

Sproul, R. C. (2000). Kebenaran-kebenaran Dasar Iman Kristen. Malang: SAAT.

Tangkudung, C. P. (2013). MAKNA KATA PEMBEBASAN DAN HUBUNGANNYA DENGAN SABAT DALAM LUKAS 4:18, 19. 2(1), 45-49.

Tirtanadi, R. (2015). PERAYAAN SABAT MENURUT JOHN CALVIN. VERBUM CHRISTI, 2.

VanGemeren, W. (2016). Progres Penebusan. Surabaya: Momentum.

Waruwu, E. (2020). Peranan Hari Sabat Bagi Kehidupan Orang Percaya Masa Kini. Fidei: Jurnal Teologi Sistematika dan Praktika, 3(2), 246-267. https://doi.org/10.34081/fidei.v3i2.106 